\title{
Lessons Learned from International Research Partnerships
}

Prem S. Paul, Vice Chancellor for Research \& Economic Development Charles Wood, Director of the Nebraska Center for Virology

John Yohe, Director of the International Sorghum and Millet Program

University of Nebraska-Lincoln

I nternational research partnerships have played a critical role in increasing food availability in many developing countries. Among the most successful examples of such partnerships is the Green Revolution, which had significant impact upon developing nations like Mexico and India. During the early 1940s, Mexico imported half of its wheat; India experienced widespread famine during 1963. But as a result of the Green Revolution, Mexico became self-sufficient in terms of crop production by 1956 and was exporting half a million tons of wheat by 1964. Similarly, India became self-sufficient with the assistance of the international research community and funding from the Rockefeller and Ford Foundations. Today, India annually exports 4.5 million tons of rice. Irrigation, fertilizer, and seed technologies were keys to these international successes.

The University of Nebraska-Lincoln (UNL) - like many of America's land grant institutions - has a long tradition of forming highly successful international partnerships to help train scientists and build in-country educational and research capacity. One example of UNL's successful partnerships led to the establishment of a new university in Turkey. Mustafa Kemal Ataturk, Turkey's founding father, had aspirations for the creation of a strong university to educate Turkish citizens; UNL helped start this new university during 1957. A large number of UNL faculty traveled to Turkey to help develop Ataturk's academic programs, train faculty, and educate students. Many Turkish faculty members came to Nebraska and received their training at UNL before joining Ataturk's faculty ranks. Today, Ataturk University is a thriving higher education institution with 17 faculties (colleges), 2,446 faculty staff, and 42,000 students. One of us (Prem Paul) represented UNL at Ataturk's $50^{\text {th }}$ anniversary celebration during the summer of 2007. During this celebration, UNL and its faculty were hailed as key to the start and success of Ataturk University.

In this paper, we summarize two of UNL's current international programs: collaborative partnerships focused on infectious disease in Zambia and China and the INTSORMIL program in Africa. We highlight lessons learned from these two efforts to inform the creation and foster the success of other international partnerships.

Research Partnerships on HIV Research in Zambia

For more than a decade, UNL has enjoyed productive research and training collaborations with Zambian 
partners. Charles Wood, director of the Nebraska Center for Virology, works with University of Zambia colleagues to conduct HIV/AIDS research. Dr. Wood has built strong ties with the University of Zambia's College of Medicine, the University Teaching Hospital (UTH), and the Zambian Ministry of Health. As a background, Zambia is one of the most urbanized countries in Africa, and it has one of the lowest population-to-land ratios on that continent. The country is approximately half the size of Europe and home to almost 11 million people. Lusaka, the capital of Zambia and home to the University of Zambia (UNZA), has an estimated population of more than 2 million individuals. Zambia has mining and agriculture as its major industries. The goal of the UNL-UNZA partnership is to build capacity to better confront infectious disease, especially HIV/AIDS and AIDS-associated diseases. Dr. Wood and his partners train in-country health care providers and researchers, enhance the Zambian research and training infrastructure, and develop additional collaborative research and educational projects.

Dr. Wood's collaborations with Zambia started 12 years ago when he was on faculty at the University of Miami and helped train the late Dr. Gonapati Bhat (1996) and Dr. Chipepo Kankasa (1997) through the NIHsupported Fogarty AIDS International Training and Research Program. When Dr. Bhat returned to Zambia, he became Head of Pediatrics at UTH and initiated a collaborative research project with Dr. Wood on Kaposi's sarcoma and human herpesvirus-8. The collaboration was successful and led to a number of subsequent collaborations. It provided funds for Dr. Kankasa (who had since returned to Zambia) to study perinatal transmission of HIV and a human herpesvirus known as HHV-8, which is linked to an AIDS associated cancer: Kaposi's sarcoma.

This collaboration has led to a number of research grants from NIH (e.g., the National Cancer Institute, the National Institute of Allergy and Infectious Diseases, the National Institute for Mental Health, and the Fogarty AIDS International Training and Research Program). UNL's grant is one of only 25 Fogarty International Training and Research Programs on HIV/AIDS in the U.S. A total of 33 individuals have been trained at UNL with this grant since its initiation during 2000 (two are currently in the program and 30 of them have returned to Zambia). The training program's ultimate aim is to help biomedical personnel in Zambia slow or halt HIV transmission and minimize the negative health effects of HIV/AIDSrelated malignancies and diseases. To date, the program has focused on training personnel, developing healthcare capacity and infrastructure, and leveraging grant funds to build incountry training and treatment programs focused on HIV/AIDS and other associated diseases, including the monitoring of anti-retroviral treatment (ART) resistant viruses. Important collaborations with other HIV/AIDS programs have developed under the leadership of former Fogarty fellows (e.g., Drs. Bhat, Kankasa, and Tendai M'soka). Zambia's Ministry of Health is so pleased with the program's successes 
that it uses the Nebraska Program as a model of U.S.-Zambian collaboration.

The infrastructure built through the Nebraska-based Fogarty training program has expanded from supporting training on opportunistic infections and cancer to the pressing need to monitor the development of HIV drug resistance upon the recent roll-out of large-scale ART programs. This expansion facilitated and resulted from successful integration with other in-country initiatives. For example, President Bush's Emergency Plan for AIDS Relief (PEPFAR) partnered with Dr. Kankasa and the UTH Department of Pediatrics to provide support for a Pediatric Center of Excellence (PCOE), which is dedicated to ART and follow-up care of HIV infected children.

The UTH infrastructure was built from scratch 12 years ago (before initiation of the Fogarty training program). At that time, there was no office space, telephone line, computer, internet access, laboratory, or dedicated study clinic. Now there is a centralized and dedicated training laboratory and clinic, satellite and FTP site linkages, and wireless internet, all supporting a number of projects and training efforts. A state-of-the-art 3,000 sq ft molecular virology laboratory was completed in 2005 in response to the need for laboratory support for projects and training efforts related to the scale-up of Zambia's ART program. The laboratory was made possible with support from the Nebraska Center for Virology and through different ongoing projects conducted by Drs. Kankasa and M'soka.

Current Collaborative Research in China
UNL has a number of collaborations with various Chinese research and education institutions, including Xian Jiaotong University in Shanghai, Zhejiang University in HangZhou, and Nankai University in Tainjin. Research and training collaborations have been set up with Nankai University, a public university under the jurisdiction of the Chinese Ministry of Education. Nankai is a comprehensive university with a curriculum that includes the humanities, natural sciences, technology, life sciences, medical sciences, and the arts. Nankai has 18 colleges and schools and offers 71 bachelor's degree programs, 206 master's degree programs, and 117 Ph.D. programs. Total enrollment stands at approximately 12,000 undergraduate students and 9,000 graduate students. Nankai is among the top 10 universities in China.

Dr. Wood has a history of training and research collaboration with Nankai dating back 22 years. Among his former trainees include Professor Yunqi Geng, who has served as the Vice President of Nankai and who is currently the InCountry Coordinator for Nebraska's Fogarty Training Program in China. Nankai made a commitment to strengthen biomedical research in its School of Medicine by developing a stronger partnership with the institution's College of Life Sciences. Because Nankai was interested in 1) building on the ongoing basic virology research conducted in its College of Life Sciences to develop an HIV/AIDS research agenda and 2) establishing the Nankai AIDS Institute, a partnership between UNL and Nankai seemed natural. Even though the Chinese 
component of the Nebraska Fogarty Training Program did not start until 2003, the program already has provided training for 13 Chinese fellows (10 of them have returned to China and three are currently being trained in Nebraska). So far every fellow who has completed the training program has returned home, resumed their former post, and actively engaged in HIV/AIDS and AIDSassociated disease research. Our returning Chinese fellows are not only actively publishing, but they also have received a number of competitive research grants, including the Global Health Research Initiative Program award and several prestigious Sino National Science Foundation research grants.

Our collaborations with Zhejiang University and University of XianJiaotong are developing and are addressed in another presentation.

International Sorghum and Millet Collaborative Research Support Program (INTSORMIL)

INTSORMIL is a U.S. Agency for International Development (USAID) program established in 1979 to provide research and training support to developing countries. The global INTSORMIL program involves 17 U.S. scientists at six universities and the USDA and 23 host country national research programs in 18 countries throughout East Africa, West Africa, Southern Africa, and Central America. Global strategies of the INTSORMIL program are:

- Sustainable crop production systems

- Sustainable plant protection systems
- Germplasm enhancement

- Market-focus

- Crop utilization

- Technology commercialization

- Building national agricultural systems

UNL has led the INTSORMIL since its inception and successfully won the 2006 renewal competition. Other partners in the current Collaborative Research Support Program (CRSP) are Kansas State University, Ohio State University, Purdue University, Texas A\&M University, West Texas A\&M University, and USDA-Agricultural Service, Tifton, GA. Like UNL, Kansas State University, Purdue University, and Texas A\&M University have been partners throughout the program's existence. Other universities have participated based on program needs and focus and the interests and relative strengths of those universities in the areas of selected focus. The focus of the current agreement is sorghum, millet, and other grains (e.g., tef, fonio and finger millet). Multiple disciplines are represented among the collaborative team, including: production-marketing specialists, food processing scientists, animal nutritionists, biochemists, entomologists, plant pathologists, weed scientists, and technology transfer specialists.

The focus of INTSORMIL is on increasing food security and promoting market development of sorghum, millet, and other grains through targeted basic and applied research, education, short term training, and technology transfer to promote adoption and economic impact. The approach is to conduct research 
relevant to the local problems of host countries and in collaboration with host institutions and involves regional, interdisciplinary and multiorganizational teams. The program has been well received by the participating countries. It has supported 873 foreign graduate students and 211 postdoctoral fellows and visiting scientists. The majority of the trained workforce has returned home with new skills, enhancing in-country capacity through research and administration. Some of the accomplishments include:

- Increase in yield and grain quality

- Enhancing utilization and value of sorghum

- Development of broad variety of sorghum and millet-based food products

- Utilization of sorghum and millet forage and grain in feed applications

Battelle recently conducted an independent assessment of the INTSORMIL program in West Africa (where the program has been active for 29 years). What was observed in West Africa was, in effect, revolutionary: the structuring of a new integrated economic development system to achieve meaningful change in rural, urban, and national living standards. The Battelle report concludes with the statement that "INTSORMIL is generating powerful impacts through projects at the village level and these should be extended to national and regional scales. INTSORMIL technologies are readily capable of more than doubling sorghum and millet output in the developing world." This is good news in light of the current food crisis.

\section{Funding Opportunities}

In the past, funding for international research partnerships was plentiful; the major funding source was USAID. Private foundations, such as the Rockefeller and Ford Foundations, also provided critical funding for international projects. However, funding from USAID has been significantly reduced, but several important CRSPs like the INTSORMIL have continued to receive support. More recently, NIH's Fogarty International Research and Training program has provided funding for infectious disease research. The U.S. Department of State also sponsors several programs that support international collaborations; similarly, the USDA Foreign Agricultural Service provides funding for international scientist and student exchanges. The National Science Foundation's Office of International Science \& Engineering provides funding for a wide range of projects that have an international scope. Competitive Fulbright fellowships support scholar exchanges as well as graduate fellowships - important resources to foster collaborations in the arts and humanities.

\section{The New Africa Initiative}

The National Association of State Universities and Land Grant Colleges (NASULGC) has launched an initiative to foster collaborations between U.S. and African universities to help African universities build capacity. NASULGC has obtained \$1 million from USAID to provide planning money to catalyze these U.S.-African partnerships. The rationale for the Africa-U.S. Higher 
Education Initiative is that with the leadership of NASULGC, additional funding will be identified to support partnerships created by USAID's initial investment.

\section{Lessons Learned}

Personal Relationships. Reviewing the best practices of successful longstanding partnerships and based on personal experience, we believe the most important factor in developing international partnerships is development of effective personal relationships. Mutual trust and common goals lead to mutually beneficial relationships; these are among the most critical factors when forming successful partnerships. This is especially essential because some Western organizations have a history of taking advantage of partnerships with developing countries to competitively compete for large grants. Then, when the grant funds run out, there is no organization, structure, or trained workforce to continue the programs - much to the chagrin of the international "partners."

Retention of talent. Retention of talent pool in partner countries is critical. International programs can have a significant impact when they focus on long-term partnerships to build incountry human resource capacity. Expanding the talent pool and building sustainable infrastructure in-country so that talent is retained is a hallmark of the most successful international collaborative partnerships. UNL's relationships with UNZA and its INTSORMIL partners are successful because of significant investment in training local talent and creating opportunities for in-country retention of that talent.

Sustainability. A major challenge facing global partnerships is development of strategies to retain incountry talent subsequent to training or technical assistance efforts. Individuals that emerge from these programs are frequently highly sought after because there is enormous competition for welltrained workers in developing nations. Program sustainability is important without it, the impact on in-country capacity is minimized. Programs that help provide new skills to local citizens can help create new businesses and improve local economies are often successful. Such efforts help sustain the programs long after seed funding is gone. Education of and buy in by local governments and stakeholders help international partnerships ultimately take ownership of such programs, which is essential to sustainability.

Leadership. Successful programs have devoted leaders who have experience working in the international arena. They also have characteristics that nurture personal relationships and follow-through with regard to the commitments they have made.

\section{Acknowledgments}

We want to thank Nathan Meier for the editorial review of this paper.

\section{References}

1. Battelle Memorial Institute - Technology Partnership Practice. (2006,

August)."INTSORMIL Economic Impact Study." Cleveland, Ohio. 